\title{
A PROFILE OF A STRATEGIC LEADER UNDER THE LEADERSHIP LAW IN THE CZECH ARMED FORCES
}

\author{
Janka KOSECOVÁ \\ Centre for Security and Military Strategic Studies, \\ University of Defence, Brno, Czech Republic \\ janka.kolacnakosecova@unob.cz \\ Petr CUPÁK \\ The Castle Guard, Czech Republic \\ petr.cupák@unob.cz
}

\begin{abstract}
From a certain point of view, it can be said that leadership and management are two different things that go hand in hand and complement each other. A number of authors dealing with this issue have long tried to define the exact boundaries between these terms, which, however, may not be entirely beneficial. It is desirable rather to seek appropriate interconnection of both areas in order to ensure the continuous development of the organization. For this reason, the concepts of strategic management, strategic thinking and knowledge management have been clarified. It is possible to apply strategic leadership in the Czech Armed Forces in the right way only by assuming that these areas are used correctly.

The aim of the article is to present the current leader profile at a strategic level under the Leadership laws, using the theory developed by major author John Calvin Maxwell. The article details the results of the questionnaire survey. The strong, average and weak areas of leadership capabilities of the organization's top management are clearly identified. In conclusion, the most important recommendations are proposed to improve the current situation.
\end{abstract}

KEYWORDS: knowledge management, leadership, leader, management strategic, strategic thinking

\section{Introduction}

Leadership can be understood as an ability or quality that enables the leader to act in an original way to influence people around him/her in his/her interests and interests of the organisation. A leader is a person who can predict and use the principles of leadership to lead his people to fulfil the vision. His followers believe in his honesty and ability to navigate and plan. With some controversy, it can be identified that he/she has charisma and can use intuition.

Currently, not only in civilian organizations but also in the military environment, the use of leadership is 
supported more and more. A certain paradox of the current situation in the Czech Republic is that the commercial environment and many renowned authors, who are examining in detail the issues of leadership, are inspired by the military environment and military leaders of the past. However, the current situation in the Czech Armed Forces (ACR) is different and the importance of this area is re-emerging. The weak point is that no Leadership controllers have been created here, and the Leadership Doctrine is missing. For this reason, it is advisable to be able to identify the profile of strategic leaders and subsequently to create appropriate conditions for their education and development.

\section{Applying the Leadership Laws in the ACR}

In every organization, in the ACR as well, it is important to understand and fulfil the principles of strategic management using strategic thinking and knowledge management. Only by combining these three areas, it is possible to create conditions for leadership education and the fulfilment of leadership principles.

\section{Strategic management is}

implemented by senior managers and it includes activities aimed at maintaining long-term coherence between the organization's mission, its strategic goals and available resources, as well as between the organization and the external environment in which the organization operates. Organizational success can be achieved by fulfilling the strategy, which is the way from vision to results. "Vision, creation of corporate strategy and creation of management conditions and others for its realization is the dominant of leadership" (Stýblo, 2012, p. 21).

Strategic thinking can be presented in different definitions. "Strategic thinking is the use of analogies and qualitative similarities to the creative development of new ideas and the formation of actions based on new learning" (Stacey, 2007). In military matters, the result of strategic thinking is: "the art of overcoming the adversary knowing that the adversary is trying to do the same thing to you" (Dixit \& Nalebuff, 2008). It is very easy to say that strategic thinking is thinking about strategy and therefore it is necessary that in the field of leadership, leaders can use the strategic thinking to fulfil the vision.

Knowledge management is a very complex area, and leaders will certainly gain an advantage when they can use not only explicit but also implicit and especially tacit knowledge (Nonaka \& Takeuchi, 1995). When military leaders are supposed to be personalities who are followed by subordinates, they should be able to acquire, process, and then use tacit information. It is a personal knowledge arising from the interaction of personal experience, thought, intuition and imagination of a particular individual or group of people. Despite the fact that this knowledge is very difficult to formalize and cannot be formalized in the concept of some authors (Polányi, 2009), it is a great challenge for organizations to learn and share this knowledge, in which case the organization has a significant competitive advantage.

\section{Application and Evaluation of the Questionnaire Survey}

In order to identify the strategic leader profile in the military environment, the questionnaire survey method was used and semi-structured interviews were then conducted. The questionnaire survey was conducted in May 2017 to identify the strategic commander's profile under the 21 Laws of Leadership (Maxwell, 2007). A survey sample of respondents was obtained by a purposeful selection method. These were professional soldiers, in particular commanders in the rank of Colonel, who work at strategic level and the 
length of their service ranges between 20-33 years. In the research group, 32 people were approached and the completed questionnaire returned from 32 people, representing an unusual $100 \%$. This fact can be attributed to the personal approach that was chosen when addressing the respondents. The research sample represents a significant percentage of the total number of colonels operating at the strategic level in the ACR.

The aim of the questionnaire survey was to find the answer to the research question: What is the profile of a strategic leader at the Ministry of Defense according to the laws of leadership? A more detailed evaluation is shown in Table no. 1

Table no. 1

Results of the questionnaire survey

\begin{tabular}{|c|c|c|c|c|c|c|c|c|c|c|c|c|c|c|c|c|c|c|c|c|c|c|c|}
\hline \multirow{2}{*}{ 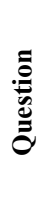 } & \multirow{2}{*}{ 疍 } & \multicolumn{9}{|c|}{ The number of answers } & \multirow{2}{*}{ 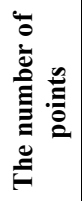 } & \multirow{2}{*}{$\begin{array}{l}\tilde{0} \\
\stackrel{0}{0} \\
\tilde{\Xi}\end{array}$} & \multirow{2}{*}{ 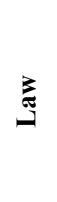 } & \multicolumn{9}{|c|}{ The number of answers } & \multirow{2}{*}{ 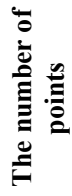 } \\
\hline & & 1 & 2 & 3 & 4 & 5 & 6 & 7 & 8 & 9 & & & & 1 & 2 & 3 & 4 & 5 & 6 & 7 & 8 & 9 & \\
\hline 1 & \multirow{3}{*}{1} & 2 & 8 & 8 & 4 & 2 & - & - & 4 & 2 & \multirow{3}{*}{5} & 31 & \multirow{3}{*}{11} & 2 & 4 & 4 & - & - & - & 10 & 8 & 4 & \multirow{3}{*}{6,4} \\
\hline 2 & & 4 & 10 & 4 & 2 & - & 4 & 2 & 4 & 2 & & 32 & & 6 & - & - & 2 & 4 & 10 & 6 & 4 & - & \\
\hline 3 & & 4 & - & - & - & 6 & 2 & 6 & 12 & 2 & & 33 & & - & - & - & - & 2 & - & 12 & 6 & 12 & \\
\hline 4 & \multirow{3}{*}{2} & - & - & - & - & 2 & 6 & 8 & 10 & 6 & \multirow{3}{*}{6,6} & 34 & \multirow{3}{*}{12} & - & 2 & 2 & 2 & 10 & 6 & 8 & 2 & - & \multirow{3}{*}{5,5} \\
\hline 5 & & - & - & - & - & 4 & 4 & 14 & 10 & & & 35 & & 6 & 2 & 4 & 4 & 2 & 2 & 8 & 4 & - & \\
\hline 6 & & - & - & 2 & 4 & 12 & & 10 & 2 & 2 & & 36 & & - & - & - & - & 0 & 4 & 10 & 8 & 4 & \\
\hline 7 & \multirow{3}{*}{3} & 4 & 8 & 8 & - & 6 & - & 6 & - & - & \multirow{3}{*}{4} & 37 & \multirow{3}{*}{13} & - & 2 & 4 & 2 & 2 & 4 & 10 & 6 & 2 & \multirow{3}{*}{6,8} \\
\hline 8 & & 12 & 6 & 4 & - & - & 4 & 6 & - & - & & 38 & & - & - & - & - & - & 2 & 4 & 12 & 14 & \\
\hline 9 & & 2 & 2 & 8 & 2 & 2 & 2 & 2 & 8 & 4 & & 39 & & - & 4 & 2 & 2 & 4 & - & 8 & 8 & 4 & \\
\hline 10 & & - & - & 2 & - & 2 & 4 & 6 & 6 & 12 & & 40 & & - & - & - & - & - & - & 6 & 10 & 16 & \\
\hline 11 & 4 & - & - & - & 2 & 6 & 4 & 2 & 14 & 2 & 6,8 & 41 & 14 & 6 & 2 & 2 & 2 & 8 & 2 & 6 & 4 & - & 6,2 \\
\hline 12 & & - & - & 2 & - & 4 & 10 & 8 & 6 & 2 & & 42 & & - & 4 & - & 4 & 4 & 8 & 6 & 6 & - & \\
\hline 13 & & - & - & 2 & - & 4 & 10 & 8 & 6 & 2 & & 43 & & - & 2 & 2 & - & - & 10 & 2 & 8 & 8 & \\
\hline 14 & 5 & - & - & - & - & 2 & 8 & 4 & 4 & 14 & 7,3 & 44 & 15 & - & - & - & - & - & - & 8 & 12 & 12 & 7 \\
\hline 15 & & - & - & - & - & 4 & 2 & 4 & 12 & 10 & & 45 & & 2 & - & 2 & 4 & - & 6 & 4 & 14 & - & \\
\hline 16 & & - & - & - & 2 & 22 & 6 & 8 & 12 & 2 & & 46 & & - & - & 2 & 4 & 2 & - & 16 & 6 & 2 & \\
\hline 17 & 6 & - & - & - & - & - & - & 6 & 14 & 12 & 6,6 & 47 & 16 & - & - & - & 2 & 2 & - & 4 & 12 & 12 & 7 \\
\hline 18 & & 4 & 8 & - & 2 & 2 & 6 & 6 & 4 & - & & 48 & & 2 & - & - & - & 4 & 4 & 10 & 10 & 2 & \\
\hline 19 & & 4 & 4 & 4 & 2 & 8 & 4 & 6 & - & - & & 49 & & 6 & 16 & - & - & 4 & 6 & - & - & - & \\
\hline 20 & 7 & - & - & - & - & - & 2 & 8 & 8 & 14 & 6,6 & 50 & 17 & - & 2 & 4 & - & 10 & 8 & 6 & 2 & - & 5,1 \\
\hline 21 & & - & - & - & 2 & 2 & 2 & 6 & 14 & 6 & & 51 & & - & - & - & - & 2 & 8 & 8 & 10 & 4 & \\
\hline 22 & & - & - & - & 2 & - & 6 & 10 & 12 & 2 & & 52 & & 2 & 2 & - & 2 & 4 & 2 & 6 & 14 & - & \\
\hline 23 & 8 & - & - & - & - & 10 & 8 & 8 & 6 & - & 6,8 & 53 & 18 & - & - & - & - & 4 & 2 & 6 & 14 & 6 & 6,4 \\
\hline 24 & & - & - & - & 2 & 4 & 4 & 20 & 2 & - & & 54 & & 4 & 2 & 2 & 2 & 4 & 2 & 8 & 8 & - & \\
\hline 25 & & - & - & - & - & 8 & 8 & 8 & 4 & 4 & & 55 & & - & - & - & 2 & 10 & 4 & 8 & 4 & 4 & \\
\hline 26 & 9 & 2 & 2 & - & 2 & 4 & 8 & 10 & 4 & - & 6 & 56 & 19 & 2 & - & 4 & 2 & 6 & 6 & 6 & 6 & - & 6,3 \\
\hline 27 & & 2 & - & 2 & - & 12 & 4 & 6 & 6 & - & & 57 & & - & - & - & - & 8 & 6 & 6 & 8 & 4 & \\
\hline 28 & & - & - & - & 2 & - & 2 & 12 & 10 & 6 & & 58 & & - & - & - & 2 & 6 & 6 & 12 & 4 & 2 & \\
\hline 29 & 10 & - & - & - & 2 & 6 & 6 & 6 & 10 & 2 & 6,6 & 59 & 20 & - & 8 & 4 & 6 & 10 & - & 2 & 2 & - & 5,8 \\
\hline 30 & & 6 & 4 & - & 4 & 6 & 4 & 8 & - & - & & 60 & & - & 4 & - & - & 2 & 2 & 8 & 10 & 6 & \\
\hline & $\mathrm{V}$ & $y$ we & & & & Slig1 & $y a b$ & ve a & rage & & & 61 & & 2 & - & - & - & 4 & 6 & 2 & 12 & 6 & \\
\hline & & Veak & & & & & & & & & & 62 & 21 & - & 2 & - & - & - & 4 & 4 & 16 & 6 & 7,7 \\
\hline & & erag & & & & & & & & & & 63 & & - & - & - & - & - & - & - & 12 & 20 & \\
\hline
\end{tabular}

The Leadership questionnaire (Maxwell, 2007), which contained 63 queries that provided answers to 21 leadership laws on the basis of which the evaluation was carried out. Looking at the results of respondents, it is obvious that they are predominantly in the area of average values.

\section{Law 1 - The Law of the Lid}

Respondents have achieved the value of 5 for this law, which is average, at the lower limit in this area of leadership, but they have another potential for growth to be used. The result for this law is that management has a given lid which can work as a brake in the organization's development. In the ACR, 
there are precisely defined goals that at the same time can mean a certain lid that hampers the further development of the organization heading behind successful frontiers, as the leader is satisfied only by the fulfillment of the assigned tasks.

\section{Law 2 - The Law of Influence}

Respondents reached the value of 6.6 for this law. From this result, it can be said that there is an additional potential in the organization for the growth of commanders at the strategic level that needs to be utilized. When evaluating this result, it is possible to identify that strategic commanders achieve the ability to influence their subordinates not on the basis of their formal position, but just for their natural influence alone. This can be evaluated positively and with the help of appropriate tools and training it is suitable to further develop this key principle of leadership.

\section{Law 3 - The Law of Process}

Respondents have achieved the value of 4 for this law, and this is the weak side that needs to be worked on. The belowaverage result for this area of leadership is a sign that the management of the organization does not pay enough attention to the development of their own abilities. Leadership is a matter of everyday access to it, when the leader is trying to learn something new every day or trying to gain new information and builds his abilities.

\section{Law 4 - The Law of Navigation}

Respondents have achieved the value of 6.8 for this law. The resulting value in this area shows that the management of the organization is able to set goals to its subordinates in a sufficiently clear and effective way, so as to avoid major problems in achieving them. At the same time, the achieved value indicates that there may be improvements in this area that would increase efficiency in effective navigation and management of the organization and its employees.

\section{Law 5 - The Law of Addition}

Respondents achieved the value of 7.3 for this law on a scale of 1 to 9 , which makes them above the average in this area of leadership. As the survey results show, the management's ability to add value to its subordinates is slightly above the average. This clearly indicates that top management has the incentive to support its subordinates, but there is still a space for improving their approach to employees.

\section{Law 6 - The Law of Solid Ground}

Respondents achieved the value of 6.6. The average value achieved in this research area suggests that the leaders themselves do not attach great importance to maintaining the permanent confidence of employees in management, i.e. in themselves. They do not consider it beneficial to establish close contact with employees, which may be reflected in the extent of fulfillment of commitments.

\section{Law 7 - The Law of Respect}

Respondents achieved the value of 6.6 for this law. There is still the potential for further growth that needs to be utilized. From the achieved value in this area it follows that the management of the organization could be followed by its subordinates at a far higher level which would certainly lead to higher efficiency of the entire organization. It is obvious that the management creates the conditions for showing mutual respect. In addition, a program is created that defines the rules of respect for its employees who, in a way, benefit from this program

\section{Law 8 - The Law of Intuition}

Respondents achieved the value of 6.8 for this law. The intuition and the ability to decide on the basis of experience is based on the result of the survey developed at the management of the organization to a slightly above average level, which gives considerable space for 
improvement. Undoubtedly, it is a great challenge for the organization to learn to use knowledge in a comprehensive way and to be able to apply a rational and intuitive approach to processing knowledge and introducing into practice using all available knowledge management tools. When dealing with poorly structured problems that lack information, or even those issues that require new and unusual solutions and cannot be achieved with logical procedures alone, the use of thought processes can be described as intuitive.

\section{Law 9 - The Law of Magnetism}

Respondents achieved the value of 6 for this law. The result for this area shows that the management of the organization is not quite unequivocally inclined to have the subordinates who will follow them and will have similar skills and abilities as they themselves. As a result, it may mean that employees do not completely fulfill the vision of the organization's management of efficiency and effectiveness.

\section{Law 10 - The Law of Connection}

Respondents achieved the value of 6.6 for this law. In this area of leadership, there is the potential for further growth that needs to be utilized. The result at the very limit of the average indicates that the management of the organization in most cases enforces its opinions rather authoritatively, often without consulting the subordinates. However, the authoritative style is not bad for the military environment, but the question is whether it is necessary to apply this style on a strategic level.

\section{Law 11 - The Law of the Inner Circle}

Respondents achieved the value of 6.4 for this law. The result suggests that the management of the organization is aware of the value of employees and knows that achieving the set goals is not always their merit but it is teamwork. In evaluating this law, it is necessary to take into account the previous law. In such case, it is identified that the organization's top management should focus more on selecting their employees via selecting procedures and, subsequently, on improving personnel policy.

\section{Law 12 - The Law of Empowerment}

Respondents achieved the value of 5.5 for this law. The principle of power transfer is not applied much in the organization, and employees are generally not charged with decision-making and are therefore not exposed to the risks associated with them. Largely, the management of the organization limits the growth of its employees, who cannot gain experience and continue to develop themselves in terms of leadership. However, the situation appears to stem from the mission of ACR.

\section{Law 13 - The Law of the Picture}

Respondents achieved the value of 6.8 for this law. The results in this area show that the management of the organization is making a great deal of effort to comply with the commitments and practices according to established models.

\section{Law 14 - The Law of Buy-In}

Respondents achieved the value of 6.2 for this law. The management is aware of the need for clear visions for the proper functioning of the organization, but they do not consider it important to acquire at the same time the favor of their subordinates who are closely related to the enforcement of visions. Here again, it is possible to assume that the situation reflects tightly set rules in the military environment.

\section{Law 15 - The Law of Victory}

Respondents achieved the value of 7 for this law. As it results from the responses, the management of the organization is aware of its responsibility for achieving the goal and tries to tune its subordinates in the same way. However, if management is to make sacrifices to help achieve this goal, they are usually unwilling to make these sacrifices, rather if necessary. 
Law 16 - The Law of the Big Mo

Respondents achieved the value of 7 for this law. The ability of the organization to impress the employees positively and to generate the necessary impetus to develop new projects or to start up already running tasks is very good. This is not a strong side, but as, the result shows, leadership is very close to become a strong player in this area.

\section{Law 17 - The Law of Priorities}

Respondents achieved the value of 5.1 for this law. Management's ability to prioritize, according to survey results, almost approaches the weakness area. The area of improvement is, according to the survey, the ability to set priorities and to make decisions that are more effective on the importance of individual tasks, which would further be reflected in the effectiveness of their fulfillment.

\section{Law 18 - The Law of Sacrifice}

Respondents achieved the value of 6.4 for this law. Willingness to grow as a leader that brings about compromises, sacrifices, and temporary loss of privileges or rights is a great personal risk, but it is the driving force behind efficiency and career growth.

\section{Law 19 - The Law of Timing}

Respondents achieved the value of 6.3 for this law. According to the results describing the timing area, it can be concluded that the organization's ability to timely plan its intentions is rather average. The sense for right timing requires proper capabilities and experience of the commanders.

\section{Law 20 - The Law of Explosive Growth}

Respondents achieved the value of 5.8 for this law. According to survey results, management is not clearly convinced of the fact that if they spend their time preparing other leaders, their organization will grow much faster. It is obvious that the readiness to devote time to training and preparing its successors or other leaders is not very much followed in the organization. Although ACR has built a network of training and education programs, according to the results of the questionnaire survey, they probably are not focused on the education of followers or other leaders. Possibly, they are not taught for so long to affect existing strategic leaders.

\section{Law 21 - The Law of Legacy}

Respondents achieved relatively high values of 7.7 on a scale from one to nine, which makes them strong in this area. They should make the most of their abilities and try to pass on their knowledge to others. Some uncertainty can be derived for this role, but it is the strongest item in all 21 Laws of Leadership, which shows that the strategic commanders of the organization are willing to find their successors and devote themselves to.

\section{Discussing the Results}

The research results provide a clear profile of the current strategic level leader in ACR, where the biggest weakness is its ability to manage the process of educating leaders. The process of education in this field is improving nowadays, but a wellestablished model of leadership training began in an accredited form of Master's Degree Study Program "Management and Use of the Armed Forces" in September 2014. In addition, the Strategic Leadership Program was introduced at the General Staff Course and the Senior Officer Course in September 2014.

It is possible to evaluate that the process of preparing personnel in the field of leadership in the ACR has been realized for a relatively short time, and at the earliest in 2020 it will be possible to evaluate the benefits of these study programs in the whole area due to the length of study. Based on interviews conducted subsequently it has 
been identified that the area of leadership is not used even in selection procedures in the defense sector. On the other hand, the strongest side of existing leaders at the strategic level is in the Law of Legacy, which is a positive fact because the existing leaders are willing to teach, educate and pass on their experiences to their future followers. They have no issues with sharing knowledge and are approachable as far as educating their followers is concerned; which, if the learning process is properly interconnected, is likely to eliminate the mediocrity in this area identified in the questionnaire survey.

\section{Recommendation}

The organization has a well-defined vision and strategic goals. Research results show that the vision is not shared across the whole organization. It is recommended to strengthen the activities of forwarding the vision to all employees of the ministry using common ideals, where the role of ACR is definitely a symbol of democracy and state sovereignty. It is appropriate to clarify the strategic objectives planned in such a way that individuals understand and accept them as their own objectives.

With regard to Law no. 6, it is advisable to use organized activities, such as joint training, as well as sports activities to build mutual trust between individual workers. Such activities are organized on a regular basis, but it is appropriate to build natural relations in the context of these activities and try to abandon the existing formal concept.

A very important point for removing identified weaknesses is also the ability to set priorities of importance and the order of meeting strategic goals.

\section{Conclusion}

Due to the introducing the leadership training in military education, the conditions for applying ACR principles and leadership laws have been improving since 2014. The results of the set educational system will be possible to evaluate in 2020 .

Despite the average result of the questionnaire survey, it is demonstrable that the organization has more potential and growth prerequisites to use. Support from existing commanders at the strategic level was also expressed by their highly accountable approach to the processing of questionnaires when $100 \%$ of questionnaires were delivered back to the research team.

\section{REFERENCES}

Dixit, A. \& Nalebuff, B. (2008). The art of strategy: a game theorist's guide to success in business \& life, New York: W. W. Norton \& Company.

Maxwell, J. (2007). 21 nevyvratitelných zákonů leadershipu: následujete je a lidé vás budou následovat, Praha: Kontakt.cz.

Nonaka, I. \& Takeuchi, H. (1995). The knowledge - creating company: how japanese companies create the dynamics of innovation, New York: Oxford University Press.

Polányi, M. (2009). The tacit dimension, London: University of Chicago Press.

Stacey, R. D. (2007). Strategic management and organisational dynamics: the challenge of complexity to ways of thinking about organisations, Harlow [u.a.]: Financial Times/Prentice Hall.

Stýblo, J. (2012). Leadership: realita nebo vize, Praha: Professional Publishing. 